\title{
Interpretação do patrimônio cultural por meio da roteirização turística da Avenida 7 de Setembro, Manaus, AM
}

\author{
Interpretation of cultural heritage through the tourist route of 7 de Setembro \\ Avenue, Manaus, AM \\ Interpretación del patrimonio cultural por medio del desarrollo de itinerario \\ turístico de la Avenida 7 de Setembro, Manaus, AM
}

\author{
Márcia Raquel Cavalcante Guimarães ${ }^{1}$ \\ Karla Cristina Ribeiro Maia ${ }^{1}$ \\ Sibelle da Silva Oliveira ${ }^{1}$ \\ Luciano Torres Tricárico²
}

Recebido em: 23/01/2019; revisado e aprovado em: 31/10/2019; aceito em: 04/02/2020.

DOI: http://dx.doi.org/10.20435/inter.v21i3.2364

\begin{abstract}
Resumo: O espaço urbano proporciona o conhecimento das diversas manifestações da sociedade materializado em suas ruas, avenidas, edificações e praças, permitindo uma melhor compreensão do processo que, ao longo do tempo, foi responsável por sua configuração. Assim, buscou-se identificar as possibilidades de interpretação patrimonial de uma cidade, por meio da Avenida 7 de Setembro, espaço representativo da história de Manaus nos períodos pré-colonial, colonial, império e república, marcados por sua construção e suas edificações. A metodologia é qualitativa, do tipo estudo de caso, com a utilização de fontes bibliográficas, documentais, de instrumentos como inventário turístico, observação e entrevista. A paisagem construída na avenida é consequência da formação social e econômica da região, onde as principais modificações ocorridas foram resultado da circulação de mercadorias e do capital financeiro de dois grandes marcos de desenvolvimento econômico e social no estado e na capital: o ciclo da borracha (1860-1930) e a criação da Zona Franca de Manaus (a partir de 1967 até hoje). Outro resultado da pesquisa é a sugestão de um roteiro turístico interpretativo pela Avenida 7 de Setembro, com a finalidade principal de diversificação da oferta turística local, valorização patrimonial e facilitação da compreensão desse espaço.
\end{abstract}

Palavras-chave: interpretação patrimonial; roteirização; avenida.

Abstract: The urban space provides the knowledge of the various manifestations of society materialized in its streets, avenues, buildings and squares, allowing a better understanding of the process that, over time, was responsible for its configuration. Thus, we sought to identify the possibilities of heritage interpretation of a city, through the 7 de Setembro Avenue, representative space of the history of Manaus in the periods pre-colonial, colonial, empire and republic, marked by its construction and its buildings. The methodology is qualitative, of the case study type, with the use of bibliographic, documentary sources, instruments such as inventory of tourism supply, observation, and interview. The landscape built on the avenue is a consequence of the social and economic formation of the region, where the main changes occurred as a result of the circulation of goods and the financial capital of two major economic and social development landmarks in the State and in the capital: the rubber cycle (1860-1930) and the creation of the Manaus Free Zone (from 1967 until today). Another result of the research is the suggestion of an interpretative touristic route through 7 de Setembro Avenue, with the main purpose of diversifying the local tourist offer, valuing heritage, and facilitating the understanding of this space.

Keywords: patrimonial interpretation; route; avenue.

Resumen: El espacio urbano proporciona el conocimiento de las diversas manifestaciones de la sociedad materializada en sus calles, avenidas, edificaciones y plazas, permitiendo una mejor comprensión del proceso responsable por su configuración. Así, se buscó identificar las posibilidades de interpretación patrimonial de una ciudad, a través de la Avenida 7 de Septiembre, espacio representativo de la historia de Manaus en los períodos precolonial, colonial, imperio y república, marcados por su construcción y sus edificaciones. Es un estudio cualitativo, del tipo estudio de caso, con la utilización de fuentes bibliográficas, documentales, inventario de la oferta turística, observación y entrevista. El paisaje construido en la avenida es consecuencia

\footnotetext{
${ }^{1}$ Universidade do Estado do Amazonas (UEA), Manaus, Amazonas, Brasil.

${ }^{2}$ Universidade do Vale do Itajaí (Univali), Itajaí, Santa Catarina, Brasil.
} 
de la formación social y económica de la región, donde las modificaciones ocurridas fueron resultado de la circulación de mercancías y del capital financiero de los marcos de desarrollo económico y social en el estado y en la capital: el ciclo del caucho (1860-1930) y la creación de la Zona Franca de Manaus (1967 hasta hoy). Otro resultado de la investigación es la sugerencia de un itinerario turístico interpretativo por la Avenida 7 de Septiembre, con la finalidad principal de diversificación de la oferta turística local, valorización patrimonial y facilitación de la comprensión de ese espacio.

Palabras clave: interpretación patrimonial; itinerario turístico; avenida.

\section{INTRODUÇÃO}

Este artigo apresenta uma reflexão sobre as possibilidades de interpretação do patrimônio cultural por meio da roteirização turística na Avenida 7 de Setembro, localizada no Centro Histórico de Manaus. Esse é um importante logradouro local, símbolo do passado e presente da cidade. Em sua extensão, destacam-se evidências dos processos de construção e transformação de Manaus em diferentes épocas.

Nesse sentido, este estudo pautou-se na hipótese de que a interpretação patrimonial é uma ferramenta para valorização e conservação do patrimônio, envolvendo o conjunto arquitetônico em que estão ambientados esses logradouros, com fins de operacionalização de um roteiro turístico. Estudos têm abordado o patrimônio na perspectiva da interpretação e da estruturação de rotas e itinerários de visitação turística, visando à valorização de construções isoladas ou em conjunto, integradas aos ambientes que as circundam. Assim, é possível planejar a valorização de uma única avenida destinada à interpretação do patrimônio cultural para turistas e residentes, como opção de lazer, entretenimento e educação para a comunidade (CARVALHO; COELHO; BONFIM, 2011), ou o patrimônio pode ser inserido num circuito turístico cultural que reúna ao mesmo tempo elementos religiosos, urbano, literário e natural (LÓPEZ, 2014) e ainda estar ligado a uma rota com os principais atrativos culturais de uma cidade, definidos a partir da perspectiva de seus moradores (IBORRA, 2016).

O aspecto fundamental da interpretação como meio para a conservação do patrimônio é enfatizado por diversos autores, ressaltando que ela deve ir além de uma simples transmissão da informação a respeito de determinado patrimônio e comunicar aos visitantes o valor e significado cultural dele, como parte importante da história de um povo ou lugar (PORTO; LEANZA; CASCONE, 2012; TOFOLO; CARDOZO, 2013; REIS; BAPTISTA; CARDOZO, 2016; CÁNOVAS, 2016). Diante desse contexto, o objetivo geral do trabalho foi identificar as possibilidades de interpretação patrimonial por meio da malha viária de uma cidade, referindo-se especificamente à Avenida 7 de Setembro. Já os objetivos específicos alicerçaram-se no propósito de contextualizar a história da avenida, levantar as suas edificações representativas e sugerir um roteiro turístico como estratégia de valorização patrimonial.

Buscou-se ainda compreender o patrimônio cultural segundo a perspectiva do contexto nacional e internacional. Leal (2016) enfatiza que, notadamente, no Brasil, a proteção ao patrimônio surge com o objetivo de construção da identidade nacional, enquanto no âmbito internacional as questões patrimoniais se desenvolvem com foco em salvaguardar a beleza, as paisagens e os sítios históricos, o que, consequentemente, resultou em importantes encontros e documentos. De forma mais precisa, apresentou-se como arcabouço teórico a relação da interpretação do patrimônio cultural com a roteirização, destacando que as referências culturais do local tornam a experiência da visitação enriquecedora. Quanto aos resultados e discussões, 
foram contextualizados o Centro Histórico e a Avenida 7 de Setembro, destacando-se questões referentes ao tombamento em nível federal e municipal, além da demonstração da significativa oferta turística existente na Avenida 7 de Setembro.

$O$ ato de viajar, ação intrínseca no turismo, pode ser um vetor de influência positiva na formação cultural da sociedade. Desta maneira, esta pesquisa justificou-se ao abordar questões relativas ao valor histórico, qualificação e conservação da memória de um lugar, aflorando sentimentos de pertencimento e valorização do patrimônio cultural em residentes e visitantes por meio da proposta de um itinerário como estratégia interpretativa, favorecendo a promoção e comercialização turística do destino Manaus.

\section{ASPECTOS METODOLÓGICOS}

Esta pesquisa está alicerçada na correlação entre o patrimônio cultural e o turismo, de modo a ressaltar as possibilidades de integração entre ambos, por meio de roteiros turísticos fundamentados na intepretação do patrimônio. O método adotado nesta pesquisa foi o indutivo. Deste modo, a análise aplicada decorreu da observação de uma realidade concreta (PRODANOV; FREITAS, 2013), retratada pela Avenida 7 de Setembro e seu entorno, tendo-a como importante logradouro da história manauara, por se localizar no Centro Histórico de Manaus, para, a partir disso, chegar-se a uma generalização sobre a valorização do patrimônio cultural por meio do turismo. Quanto à caracterização deste estudo, considerou-se como de abordagem qualitativa, aplicada, descritiva e exploratória, pois se buscou obter maior familiaridade com o tema e objeto pesquisado, além de identificarem-se as possibilidades de interpretação do patrimônio e sua valorização por meio do turismo.

Os procedimentos técnicos para o levantamento de dados foram estruturados em três etapas principais: um levantamento em campo que consistiu na realização de inventário da oferta turística da respectiva avenida e seu entorno, com base em modelo adaptado nas diretrizes e orientações do Ministério do Turismo (BRASIL, 2011); observação direta, realização de entrevistas semiestruturadas, conversas informais e participação de reuniões com membros do Conselho Municipal de Turismo (Comtur); e levantamento em sites das principais agências de receptivo turístico de Manaus sobre roteiros oferecidos. O inventário da oferta turística contribuiu para uma caracterização geral da área do entorno e da própria Avenida 7 de Setembro, no que corresponde aos seus aspectos históricos, sobre a dinâmica de atividades comerciais existentes, infraestrutura básica e turística.

As entrevistas com membros do Comtur, bem como a observação de suas atividades, revelaram informações importantes sobre o tema e objeto de estudo, desvelando circunstâncias e opiniões significativas de pessoas que têm influência direta na promoção do turismo em Manaus, entre essas, representações empresariais e governamentais. Os questionamentos e levantamentos feitos tiveram como foco as possibilidades da interpretação patrimonial por meio da roteirização turística, cujo lócus refere-se à Avenida 7 de Setembro e seu entorno. As indagações feitas foram estruturadas em torno dos principais questionamentos da pesquisa: a Avenida 7 de Setembro e seu entorno oferecem possibilidades para a realização de um roteiro turístico fundamentado na interpretação patrimonial? Esse roteiro contribuiria para a valorização do patrimônio local? Além disso, realizou-se um levantamento nas três principais agências que operam o receptivo em Manaus para identificar os roteiros turísticos oferecidos e levantar se a avenida, objeto da pesquisa, integra alguma programação e de que forma isso acontece. 
A análise e interpretação dos dados e das informações obtidos desenvolveram-se a partir das evidências observadas, relacionando-as ao referencial teórico, com ênfase nos conceitos de patrimônio, roteirização turística e interpretação patrimonial, conjuntamente com o conhecimento empírico dos pesquisadores sobre o objeto e tema. As conclusões da pesquisa buscaram responder se é possível interpretar o patrimônio por meio da malha viária da Avenida 7 de Setembro e se um roteiro turístico poderia servir como estratégia de valorização patrimonial.

Para analisar se o lócus da pesquisa tem condições adequadas à interpretação patrimonial por meio de roteiros turísticos, utilizaram-se categorias sobre interpretação patrimonial definidas pelo International Council on Monuments and Sites (ICOMOS, 2008), que foram: 1. Interpretação; 2. Apresentação; 3. Infraestrutura interpretativa; 4. Intérpretes do patrimônio e 5. Sítio de patrimônio cultural. Estes conceitos permitiram entender os elementos interpretativos possíveis para um roteiro, como aspectos históricos, socioeconômicos, ponto de início e término do roteiro, tempo e os meios referentes ao tipo de visitação, público-alvo, sua perspectiva de conjunto, os atrativos já conhecidos e consolidados e como esses podem contribuir para a inserção de outros em roteiros integrados. Os resultados foram apresentados descritivamente, segundo cada etapa definida no plano de desenvolvimento da pesquisa.

\section{A PERCEPÇÃO DO PATRIMÔNIO CULTURAL NO CONTEXTO NACIONAL E INTERNACIONAL}

Para melhor se compreender a interpretação do patrimônio proposta no presente estudo, faz-se necessário refletir primordialmente sobre a palavra patrimônio. Esta tem sua origem do latim, "patrimonium, que se referia, entre os antigos romanos, a tudo o que pertencia ao pai, pater ou pater familias, pai de família" (FUNARI; PELEGRINI, 2006, p. 10). No mesmo sentido, Castriota (2004, p. 10) complementa que a palavra patrimônio significava "o conjunto de bens de uma pessoa, o que incluía desde a sua casa, terras e utensílios até escravos, e as mulheres (que não eram cidadãs)". Choay (2001, p. 11) também reforça o sentido do antigo entendimento de patrimônio como "bem de herança que é transmitido, segundo as leis, dos pais e das mães aos filhos".

Percebe-se que, em outrora, o patrimônio era compreendido apenas como bens individuais, a herança que seria passada de pais para filhos e assim sucessivamente com as próximas gerações; não se tinha um entendimento de patrimônio no coletivo, de heranças deixadas por nossos ancestrais, que se tornariam bens representativos de uma cultura, de uma sociedade e seus marcos históricos (FUNARI; PELEGRINI, 2006; CASTRIOTA, 2004; CHOAY, 2001). No entanto, no final do século XVIII e início do século XIX, ocorreram grandes mudanças na sociedade, sendo resultados tanto da Revolução Industrial quanto da Revolução Francesa. Tais transformações também envolveram o patrimônio, pois, em ambos os momentos, muitos edifícios e monumentos foram destruídos por conta das guerras; nesse processo, ocorre grande preocupação com a conservação do patrimônio para evitar o esquecimento dos feitos do passado (CHUVA, 2012; MOURA, 2012; TORELLY, 2012; ZANIRATO; RIBEIRO, 2006).

A princípio, a noção de patrimônio se resumia às "obras e obras-primas das belas artes e das artes aplicadas, trabalhos e produtos de todos os saberes dos seres humanos" (CHOAY, 2001, p. 11). Diante desse entendimento, denominavam-se de patrimônio histórico os monumentos, edificações, documentos e objetos, ou seja, em tudo que fosse materializado de alguma forma, valorizava-se o estético, o artístico e o histórico. 
Historicamente, a preocupação com políticas para a salvaguarda dos bens patrimoniais surgiu no referido período e, com o passar dos anos, de forma a atender a diversidade de necessidades e expectativas em relação à preservação do patrimônio, importantes eventos, reuniões e documentos se desenvolveram por meio de uma cooperação internacional. "Inicialmente, a decisão do que seria considerado patrimônio recaiu sobre especialistas (arquitetos, juristas, historiadores, antropólogos, sociólogos, literatos e artistas plásticos), que passaram a determinar quais seriam os símbolos de uma nação" (VOGT, 2008, p. 15). O resultado dos eventos e reuniões foi sistematizado em variados documentos, contribuindo para a proteção do patrimônio e trazendo notoriedade mundial para o assunto. A citar nos anos 1960: a recomendação de Paris (1962), promovida pela Unesco; as normas de Quito (1967), durante reunião sobre conservação; e a recomendação de Paris (1968), resultado da 15a Conferência Geral da Unesco (LEAL, 2016; RISCADO, 2013; PEREIRA, 2012).

A partir desses acontecimentos, a política internacional sobre o patrimônio tem relevante repercussão, sendo um importante meio para reconhecimento e proteção no que diz respeito à memória e identidade que constituem a cultura de um povo. Percebe-se que o patrimônio vai além do monumento histórico, "se passa de um patrimônio histórico a um patrimônio social; de um patrimônio herdado a um patrimônio reivindicado; de um patrimônio visível, material, a um invisível, imaterial" (LE GOFF, 1998, p. 11). Grammont (2006) esclarece que o patrimônio histórico passa a integrar o conceito de patrimônio cultural, dividindo-o entre material e imaterial, ampliando as perspectivas ao considerar o conceito antropológico de cultura e todo saber/ fazer humano, como objetos, conhecimentos, capacidades e valores. Assim, o "patrimônio, na perspectiva cultural, refere-se aos relatos materiais e imateriais que compõem a memória coletiva de um povo" (DORSA; CASTILHO; SANTOS, 2015, p. 467).

Conforme o exposto, a percepção acerca da palavra patrimônio ampliou-se com o passar dos anos, bem como o valor atribuído a ela de forma coletiva, principalmente para a preservação do legado cultural para usufruto das gerações futuras. Em síntese, a expressão patrimônio cultural é compreendida como um bem herdado por um grupo social (PASSARELLI; ALVES, 2013). Contudo as questões patrimoniais no Brasil datam do período da Revolução Francesa, além de seguir os mesmos preceitos, valorizando o patrimônio histórico e artístico, em busca de uma identidade nacional (TOMAZ, 2010). "O histórico e o artístico assumem, nesse caso, uma dimensão instrumental, e passam a ser utilizados na construção de uma representação de nação" (FONSECA, 1997, p. 37). Porém, a primeira menção jurídica em relação ao patrimônio surge na Constituição de 1934, no art. 10: “Compete concorrentemente à União e aos Estados: [...] III- proteger as belezas naturais e os monumentos de valor histórico ou artístico, podendo impedir a evasão de obras de arte". Há também outro artigo que impõe proteção ao patrimônio, sendo o art. 148: "Cabe à União, aos Estados e aos Municípios favorecer e animar o desenvolvimento das ciências, das artes, das letras e da cultura em geral, proteger os objetos de interesse histórico e o patrimônio artístico do País, bem como prestar assistência ao trabalhador intelectual". A Constituição de 1934 supracitada continua a reforçar a proteção somente ao patrimônio histórico e artístico.

Passados alguns anos, "o Governo de Getúlio Vargas cria o Serviço de Patrimônio Histórico e Artístico Nacional (SPHAN - Lei 378/1937) e, por meio do Decreto-Lei n. 25, organiza a proteção do patrimônio histórico e artístico nacional por meio do tombamento dos bens" (MARTINS; VIEIRA, 2006, p. 07). O Sphan é o atual Instituto do Patrimônio Histórico e Artístico Nacional (Iphan). Por meio do referido Decreto-Lei n. 25, de novembro de 1937, há uma definição de 
patrimônio histórico e artístico nacional, além de proteção aos bens culturais brasileiros, no art. 10: "Constitui o patrimônio histórico e artístico nacional o conjunto dos bens móveis e imóveis existentes no país e cuja conservação seja de interesse público, quer por sua vinculação a fatos memoráveis da história do Brasil, quer por seu excepcional valor arqueológico ou etnográfico, bibliográfico ou artístico" (BRASIL, 1934). Nesse período, a relação entre patrimônio e cultura passa a se desenvolver, principalmente no que diz respeito às políticas de patrimônio, ocorrendo mudanças expressivas nas ações de preservação e proteção (TOMAZ, 2010; MARTINS; VIEIRA, 2006; FONSECA, 1997).

Ainda sobre as legislações de proteção ao patrimônio cultural brasileiro, a partir do disposto no art. 216 da Constituição do Brasil de 1988, tornaram-se mais rigorosas as intervenções de proteção e salvaguarda legal sobre o patrimônio cultural brasileiro, sendo seu conceito definido como: "bens de natureza material e imaterial, tomados individualmente ou em conjunto, portadores de referência à identidade, à ação, à memória dos diferentes grupos formadores da sociedade brasileira" (BRASIL, 1988). Percebe-se que a Constituição de 1988 responde às demandas, no que tange ao reconhecimento da pluralidade da cultura brasileira, "para fins de tutela estatal, a partir da delimitação de um conjunto de bens culturais preserváveis por meio da tutela jurídica" (DANTAS, 2015, p. 34).

Assim, os bens materiais e imateriais são considerados Patrimônio Cultural Nacional ao serem devidamente tombados ou registrados, além de que os estados e municípios também têm sua própria política de preservação. Em síntese, as legislações asseguram o patrimônio cultural em esfera internacional, nacional, estadual e municipal, garantindo a preservação, proteção e maior permanência dos bens materiais e imateriais, tangíveis ou intangíveis, culturais ou naturais (ZANIRATO; RIBEIRO, 2006). Como contraponto, para Rodrigues (2015, p. 314), existe a necessidade de "desmascarar a forma como é feita a patrimonialização, que pode congelar um determinado bem", ou seja, o perigo de espetacularização urbana em determinadas localidades, pois existe uma ilusão de que os processos de patrimonialização possam integrar uma rede de cidades turísticas, sem se preocupar essencialmente com a preservação e conservação da identidade e autenticidade desses lugares. Assim, a mesma autora valida esse pensamento ao afirmar que, conceitualmente, patrimônio deve remeter àquilo que se refere a nossa identidade - entornos culturais, as tradições, formas de vida, linguagem - e ainda deve ser pensado como símbolo de qualidade de vida a serviço dos cidadãos.

O nascedouro da política de proteção patrimonial, nacional ou internacional, deu-se na visão do individual, o que nos traz uma reflexão para as questões do tombamento de conjunto, e não apenas de monumentos, prédios ou casarios, mas toda a malha viária em que estão inseridos, sendo essa de igual importância no processo da espacialização da edificação e relevância do lugar para o turismo.

\section{INTERPRETAÇÃO DO PATRIMÔNIO CULTURAL COM FOCO NA ROTEIRIZAÇÃO}

Conhecer uma cidade pode ser uma experiência fascinante, envolvendo histórias e elementos marcantes sobre a sua cultura e ambientes característicos. Nesse contexto, o patrimônio cultural existente figura como um dos elementos de grande atratividade para os turistas, bem como para a memória e etnicidade da sociedade constituída nesses espaços. A interpretação patrimonial objetiva, entre outros aspectos, ser um meio de transmissão da 
informação sobre o patrimônio visitado, além de possibilitar o enriquecimento da experiência vivida, facilitando o acesso aos fatos e aspectos marcantes da história de um lugar. Pupo (2011) diz que patrimônio é sinônimo de investigação, registro e interpretação de objetos materiais e imateriais, como centros históricos, conjuntos de monumentos, de edifícios, de seus pertences móveis e obras de arte, de tradições, de músicas, festas e da paisagem que os compõem.

O valor patrimonial de um elemento cultural pode ser disseminado por meio de comunicação pública, sendo parte de um processo de conservação mais amplo, envolvendo a difusão, divulgação, apresentação e a interpretação do patrimônio. O desenvolvimento de atividades interpretativas em sítios patrimoniais tem crescido, juntamente da introdução de variados meios e tecnologias da comunicação e informação em busca de promover esses logradouros, ao mesmo tempo em que valorizam e enriquecem a visitação.

Em um estudo sobre a interpretação patrimonial no sudeste da Sicília (Itália), onde Construções Tradicionais Rurais (TRBs) são parte integrante da paisagem agrícola, Porto, Leanza e Cascone (2012) consideraram que essa atividade é uma forma de promover as TRBs como patrimônio construído, tornando-as atrações, ao mesmo tempo em que preservam as características distintivas dos edifícios. O estudo sugere que uma inovação no método de interpretação patrimonial poderia ser aplicada pelas autoridades locais para o desenvolvimento do turismo cultural como forma de valorização dessas construções. Os meios de interpretação selecionados foram definidos com base nas informações obtidas por meio da análise das expectativas dos visitantes, e o roteiro estabelecido permitia aos visitantes explorar áreas rurais visitando TRBs, onde poderiam ter uma amostra dos produtos locais, ouvindo a narrativa de guias de turismo locais sobre a história e tradições, além de conhecer técnicas de construção das TRBs.

Essa experiência denota a relevância do conhecimento das peculiaridades locais em termos de atratividade histórica e cultural como insumo na formatação de roteiros turísticos, que qualificam a visitação e experiência para o turista, bem como a valorização cultural dos destinos visitados, incentivando a autoestima do residente. Então, no intuito de balizar princípios fundamentais para a interpretação, apreciação e compreensão do patrimônio pelo público que frequenta esses sítios, além da valorização do patrimônio em si, o Icomos (2008) definiu alguns conceitos básicos sobre o assunto: 1. A interpretação se refere a todas as atividades realizadas para gerar conhecimento ao público sobre o patrimônio cultural, incluindo as publicações impressas e eletrônicas, as conferências, as instalações sobre o sítio, os programas educativos, as atividades comunitárias e os programas de formação, métodos e sistemas de valorização permanente. 2. A apresentação consiste no planejamento das maneiras de comunicar os conteúdos interpretativos, incluindo painéis informativos, exposições, tipo museus, trilhas sinalizadas, visitas guiadas, multimídias e páginas na web. 3. A infraestrutura interpretativa são as instalações físicas, equipamentos e os espaços patrimoniais. 4. Os intérpretes do patrimônio dizem respeito às pessoas encarregadas pela veiculação da informação ao público que visita o patrimônio, ressaltando o valor e o significado dele. 5 . Sítio de patrimônio cultural faz referência a um local, uma paisagem cultural, um complexo arquitetônico, ou ainda uma estrutura reconhecida como sítio histórico.

No que se refere ao intérprete do patrimônio, no caso de visitas guiadas, Reis, Baptista e Cardozo (2016) ressaltam que a forma de condução de uma visita e como são passadas as informações acabam sendo fatores fundamentais para uma interpretação bem-sucedida por parte dos visitantes. Isso denota que, se o intérprete traduziu e repassou as informações de 
forma a reviver sensações e momentos nos quais os visitantes se sentiram fora de seu mundo habitual, executaram bem seu trabalho; caso contrário, se apenas repetiu informações, como um gravador ou um texto lido, a qualidade da interpretação obtida pelo visitante não será aquela esperada e, por conseguinte, a experiência vivida sofrerá deturpações.

Cabe ressaltar que a interpretação patrimonial pode ocorrer por meio de uma visita guiada por um intérprete ou ainda de maneira autônoma e independente, quando se trata de uma visita autoguiada. Em alguns casos, ocorre também de forma integrada, com um intérprete e, ao mesmo tempo, com diversos materiais, como textos, guias turísticos, mapas, placas e suporte ao visitante. "Ambas as formas de interpretação são válidas desde que elaboradas de forma correta e que atuem sob a perspectiva de uma temática, ou seja, um tema central de exposição" (REIS; BAPTISTA; CARDOZO, 2016, p. 02).

Portanto um dos pontos que devem ser observados para um bom resultado na interpretação patrimonial diz respeito aos responsáveis pela apresentação desse patrimônio, que devem conhecer muito bem o ambiente desse sítio e, ademais, saber como transmitir as informações referentes ao contexto sociocultural de formação e inserção dele na história do lugar. A interpretação é direcionada às pessoas, pois objetiva ter a atenção dos destinatários, da sociedade, mediante certas técnicas que promovam o patrimônio e seu significado por meio de meios e mensagens interpretativas. "A missão da interpretação é contribuir para a prevenção e solução de um problema: evitar a deterioração do patrimônio, em âmbito local e global" (PUPO, 2011, p. 24).

Sob essa perspectiva, a interpretação do patrimônio é um meio de promover maior aproximação entre as pessoas e o sítio, induzindo uma relação promissora para ambas as partes. Por um lado, possibilita ao público mais familiaridade com o lugar ou objeto, motivando a pertença por meio do conhecimento; por outro, favorece a perenidade do patrimônio e sua conservação. Nesse sentido, os roteiros turísticos são um meio interessante de apropriação das técnicas de interpretação patrimonial com vistas a agregar valor à experiência do turista, mas também para a valorização do patrimônio. Um roteiro é um percurso delimitado e organizado, integrando atrações que, em conjunto, apresentam similaridade ou complementaridade. Deve ser produzido levando em conta as características da oferta em geral, do público-alvo focado e das condições de integração, no que se refere à infraestrutura existente, que poderá ser favorável ou insuficiente para a efetivação do roteiro. O tempo de cumprimento do itinerário e a singularidade e representatividade dos atrativos também são fatores fundamentais para que o roteiro seja bem-sucedido.

Diante da necessidade de preservação e conservação do patrimônio cultural, é de suma importância o uso dos conceitos sugeridos pela carta de Icomos (2008) no âmbito da interpretação patrimonial que balizem a escolha de uma ou várias formas (publicações, guias turísticos, mapas, uso de intérpretes, visitas autoguiadas etc.) para a viabilização de itinerários ou roteiros turísticos, tendo sempre como foco a qualidade, autenticidade e identidade na experiência a ser proporcionada aos visitantes, sejam eles turistas ou residentes.

\section{RESULTADOS}

Esta seção apresenta aspectos históricos e atuais contextualizados no âmbito da proposta deste artigo, ao sugerir um novo olhar para a malha viária do Centro Histórico da capital manauara, 
em especial, a Avenida 7 de Setembro, a qual reúne peculiaridades e diferenciais de atratividade que podem torná-la uma nova possibilidade de roteirização turística para o destino Manaus.

\subsection{A valorização do patrimônio cultural a partir da Avenida 7 de Setembro}

A Avenida 7 de Setembro (Figura 1) faz parte do bairro Centro, pertencente à zona sul da cidade de Manaus. Parte dessa via contempla o sítio histórico, considerado o marco zero da cidade, integrando o Centro Antigo (tombamento municipal - Loman) e pertencendo aos limites do Centro Histórico de Manaus (tombamento federal - Iphan). Configura-se em uma avenida de mão única, que corta diversas ruas que dão acesso a outros bairros da cidade. Em toda sua extensão, destacam-se os patrimônios edificados, herança advinda do período da borracha, conforme enfatiza Guimarães e Pereira (2012). Os principais atrativos culturais desse período estão presentes na área central da cidade, representado pelo patrimônio edificado, como museus, teatros, centros culturais, residências, comércio, praças e parques, estes em sua maioria localizados na Avenida 7 de Setembro. Essa área é depositária da maior parte do patrimônio edificado remanescente da fundação e evolução urbana de Manaus, uma espécie de marco urbano da cidade, com valores patrimoniais distintos e complementares, em que o paisagístico e o urbanístico, o histórico e o pré-histórico estão fortemente entrelaçados como autênticos representantes do patrimônio cultural da região.

Figura 1 - Mapa com a delimitação do Centro Antigo de Manaus e o seu sítio histórico de Loman (1990), com destaque em vermelho para a Avenida 7 de Setembro

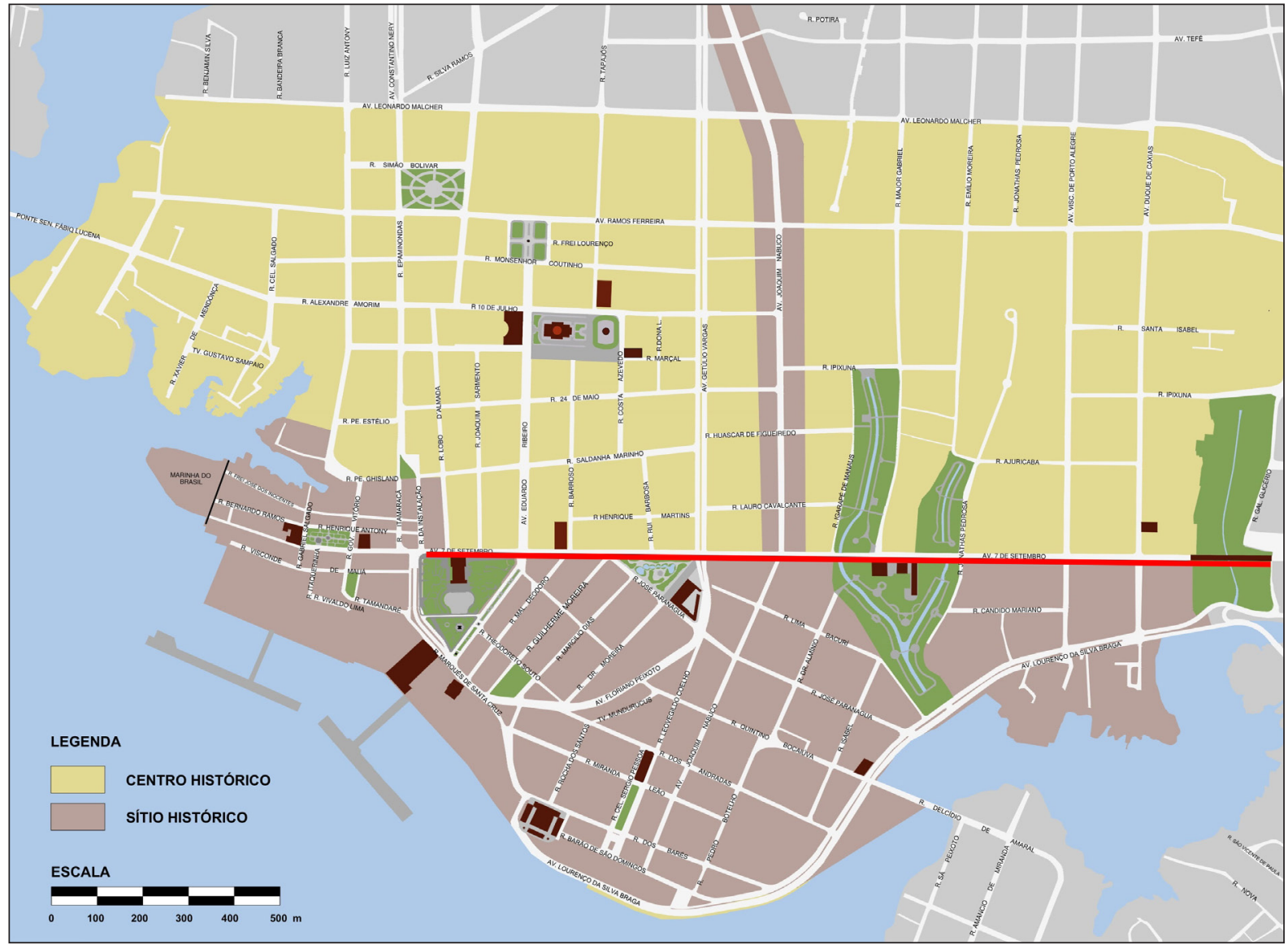

Fonte: Mapa fornecido pela Fundação Municipal de Cultura, Turismo e Eventos (Manauscult) (MANAUS, 2017). 
$\mathrm{Na}$ avenida, existe um grande adensamento de atrativos culturais individuais, contando com uma estrutura de serviços e uma infraestrutura turística que favorecem as possibilidades de implantação de atividades com foco no turismo, especificamente diversas modalidades de roteiros presenciais, autoguiados, publicações impressas ou eletrônicas a respeito da atratividade do lugar, agregando inclusive a historicidade da própria avenida dentro de uma perspectiva de conjunto com as edificações. Por meio dessa via, a paisagem se destaca devido aos patrimônios culturais relevantes para a cidade, bem como para o desenvolvimento de atividades turísticas, em decorrência de sua representatividade memorial e significativa oferta turística, tanto de atrativos quanto de serviços e estrutura.

Andrade (2008, p. 570) aborda que lugares de memória "são verdadeiros patrimônios culturais, projetados simbolicamente e podem estar atrelados a um passado vivo que ainda marca presença e reforça os traços identitários do lugar". Corroborando, a interpretação do patrimônio cultural a partir da roteirização turística é uma importante ação que reconhece a magnitude desse, valorizando e preservando a memória do lugar, gerando pertencimento e identidade espacial por meio da paisagem, pois nas localidades encontram-se "as marcas do local construídas no tempo" (GASTAL, 2006, p. 101). Identificar as mudanças temporais, as variadas ocupações do espaço e as transformações ocorridas na paisagem em toda a extensão da Avenida 7 de Setembro torna-se fundamental para o fortalecimento de vínculos com a própria identidade, uma vez que o percurso destaca uma história viva que o próprio residente local desconhece. "Há diferenciais significativos frente a outros espaços do centro urbano de Manaus, já que as origens e aspectos relativos à evolução da cidade convergem nesse local" (GUIMARÃES; PEREIRA, 2012, p. 21).

Guimarães e Pereira (2012) afirmam que o nome da Avenida 7 de Setembro faz referência ao momento histórico brasileiro, quando foi proclamada a Independência do Brasil no dia 7 de setembro de 1822. Porém, ao longo dos anos, essa avenida passou a receber diversos nomes, entre eles: Rua Direita (1787); Estrada da Cachoeirinha de Manaus ou Caminho da Cachoeirinha (anterior a 1830); Rua Liberal (entre 1831 e 1832); Rua Brasileira (1841); Rua do Sol (1844); Rua de Manaus (1866); Rua ou Estrada do General Miranda Reis (1872); Rua Brasileira (1879); Estrada ou Avenida Conselheiro Furtado (1881); Rua Wandenkolk (1890); Rua Municipal (1894 e 1895); Rua Fileto Pires (1897); Rua Municipal (1898; 1899; 1906; 1913 e 1915); Avenida 7 de Setembro (1922); Rua Dr. Edgard do Rego Monteiro (entre 1923 e 1924); Avenida 7 de Setembro (1924); Avenida Efigênio Sales (entre 1925 e 1929); Avenida Dorval Porto (193-); Avenida Juarez Távora (193-) e Avenida 7 de Setembro (193- até os dias atuais). Conforme as mesmas autoras, as mudanças no centro da cidade também atingiram a Avenida 7 de Setembro; após o declínio da borracha, acentuado a partir de 1910, veio a fase da estagnação econômica, pois não havia outros recursos que pudessem gerar desenvolvimento local. A cidade só se recuperou economicamente a partir da criação da Zona Franca, nos anos 1970, influenciando uma nova fase de desenvolvimento e alternativa econômica para Manaus, no Decreto-Lei n. 288, de 28 de fevereiro de 1967.

As necessidades comerciais impuseram a destruição de edificações históricas para construir prédios mais modernos, transformando o Centro Histórico em centro comercial; os logradouros de modo geral, inclusive a Avenida 7 de Setembro, passaram a ser usados para o comércio informal com vendas ambulantes, além do crescimento desordenado próximo aos igarapés da cidade, por meio de aumento do fluxo de migrantes para a cidade, visando a oportunidades de trabalho. Souza (2009) relata que a promessa de geração de 50.000 empregos e com uma estrutura de cidade decadente atraiu uma população de migrantes que nunca mais cessou de aportar em 
Manaus. A partir de 2006, o Programa Social e Ambiental dos Igarapés de Manaus (Prosamim) promoveu mudanças significativas na paisagem urbana do Centro Histórico, ocorrendo a retirada da população que morava em palafitas construídas no entorno dos igarapés, que cortavam a Avenida 7 de Setembro. Essa ação, destaca Guimarães e Pereira (2012), aconteceu para mudar o cenário de ocupação ilegal na área, que resultava em moradias com condições precárias e de risco, além da poluição que, consequentemente, causava forte odor e inundações.

Observa-se a relevância da Avenida 7 de Setembro, em função de ser uma área depositária, em toda sua extensão, de grande parte dos principais patrimônios culturais do Centro Histórico de Manaus, o que favorece a oportunidade de valorizar os patrimônios por meio da interpretação patrimonial, ensinando que o local é mais do que de mera contemplação, vai além, justamente por assim fornecer conhecimentos sobre a cultura e identidade a partir da percepção ao ser visitado, sendo um meio para informar sobre o contexto histórico, tanto para residente quanto para o turista. Nessa perspectiva, a avenida gera conhecimento local, enfatizando os períodos do Ciclo da Borracha, Zona Franca de Manaus e Prosamim, que foram materializados na paisagem da avenida. Tal historicidade nos permite afirmar ser esse logradouro o único a contar a história de Manaus desde o período pré-colonial, colonial, império até a república, a partir da construção da própria avenida até suas edificações, conforme Guimarães e Pereira (2012).

Fomentar uma nova imagem ao Centro Histórico, expandindo a percepção sobre o patrimônio cultural presente na cidade, para além do Teatro Amazonas, é um desafio necessário, pois a inalterabilidade em divulgar sempre a mesma coisa acaba limitando a geração de mais conhecimento sobre o patrimônio local, dificultando o surgimento de novos roteiros turísticos para explorar o Centro Histórico de Manaus. O turismo implica rearranjos espaciais, adaptação de elementos e reconfigurações da paisagem, em que, ao apropriar-se do espaço urbano, a atividade turística torna-se um dos principais agentes intervenientes da dinâmica das relações sociais estabelecidas, engendrando um processo dialético de produção de novas territorialidades (CARVALHO; COELHO; BONFIM, 2011).

Assim sendo, a valorização cultural ocorrerá a partir do momento que houver uma maior apropriação da história local. Destacar a trajetória histórica da avenida evitará perdas culturais e, principalmente, modificará o olhar sob a perspectiva de que a história que constitui Manaus é única, sendo culturalmente significativa e capaz de gerar uma ponte entre o passado e seu entorno. No intuito de direcionamento dessa nova perspectiva do olhar, Murta e Goodey (2002) mencionam que a valorização cultural é um processo de acréscimo de valor à experiência do visitante, com o fornecimento de informações e representações que exaltem a história e as características culturais e ambientais de um lugar.

É extremamente importante que o visitante possa descobrir as referências que estão ao longo do trajeto da Avenida 7 de Setembro e relacioná-las com a história local, compreendendo que o conjunto de monumentos e patrimônios que estão materializados em toda a sua extensão torna possivel uma narrativa sobre todo o processo de transformações pelo qual a cidade de Manaus passou, desde sua construção, ascensão, expansão desordenada, até investimentos modificadores de sua paisagem, entre outros processos.

\subsection{Roteiro da Avenida 7 de Setembro: um passado presente na cidade de Manaus}

Após esse relato histórico e geográfico da Avenida 7 de Setembro, a presente pesquisa pretende contribuir com a sociedade manauara e o trade turístico, colocando à disposição a 
possibilidade de operacionalização de um roteiro turístico que narre a evolução histórica e social da cidade por meio da avenida, tanto para turistas como para a população local. Porém, antes de sugerir tal proposta, fazem-se necessárias algumas abordagens teóricas que complementam as definições e especificidades do conceito de roteiro turístico.

A elaboração de roteiros turísticos pode funcionar como estratégia de desenvolvimento do destino turístico e inclusão das sociedades dentro de um processo de interação constante. Para Bahl (2004, p. 43), roteiro é como a "descrição pormenorizada de uma viagem ou itinerário, com a indicação de uma sequência de atrativos existentes numa localidade e merecedores de serem visitados". Já na visão de Boullón (2002) os roteiros têm a função, nos centros turísticos, de estruturar o conjunto. São vias de circulação selecionadas pelo trânsito turístico de veículos e pedestres, em seus deslocamentos para visitar os atrativos turísticos e para entrar e sair da cidade, possuindo importância em razão dos pontos ou lugares que une e por si mesmo. Ainda nesse contexto urbano, o estudo de Boullón (2002) menciona que as cidades podem ser reduzidas em dois grandes grupos: edifícios e espaços abertos, tendo seis pontos focais urbanos - logradouros, marcos, bairros, setores, bordas e roteiros.

Em recente pesquisa junto aos sites das principais agências que operam o receptivo turístico na capital e no material publicitário de órgãos públicos de turismo e cultura, verificouse que os principais roteiros oferecidos são basicamente visitas guiadas às edificações, city tour e sightseeing (visita panorâmica sem paradas como o city tour) no Centro Histórico. Não são oferecidas aos visitantes opções de roteiros que possam contar parte da história da cidade por meio de um passeio por uma de suas avenidas, apresentando a evolução histórico-cultural das edificações com sua malha viária.

No intuito de validação da proposta de roteirização interpretativa da Avenida 7 de Setembro, foram realizadas, no período de julho a agosto de 2018, entrevistas com os conselheiros do Conselho Municipal de Turismo (Comtur), Manaus. Criado pela Lei 424, de 8 de janeiro de 1998, e alterado pela Lei 1.884, de 13 de junho de 2014, o Conselho Municipal de Turismo é um órgão colegiado vinculado à Fundação Municipal de Cultura, Turismo e Eventos (Manauscult). Sua finalidade precípua é formular a política municipal de turismo, visando criar condições para o incremento e o desenvolvimento da atividade turística no município de Manaus. Formado por instituições e atores de relevante significância para a operacionalidade e o desenvolvimento do turismo, tem entre seus membros representados da Associação Brasileira de Agências de Viagens (Abav); Associação Brasileira dos Bacharéis em Turismo (ABBTUR); Associação Brasileira da Indústria de Hotéis (Abih); Associação Brasileira de Jornalistas de Turismo (Abrajet); Empresa Estadual de Turismo do Amazonas (Amazonastur); Câmara Municipal de Manaus (CMM); Federação do Comércio do Amazonas (Fecomércio); Federação das Indústrias do Estado do Amazonas (Fieam); Instituições de Ensino Superior (IES) em Turismo; Instituto Municipal de Ordem Social e Planejamento Urbano (Implurb); Fundação Municipal de Cultura, Turismo e Eventos (Manauscult) e Serviço de Apoio às Micro e Pequenas Empresas do Amazonas (Sebrae-AM).

Entre as 12 instituições representadas no Comtur, obteve-se o retorno de nove respondentes. Ressalta-se, também, que uma das autoras da presente pesquisa é membro do referido Conselho, como representante de uma das IES, portanto os resultados desta pesquisa refletem seu posicionamento e vivência. Quanto ao perfil dos entrevistados, oito têm a escolaridade na categoria pós-graduado e somente um tem somente o nível superior. Apenas três conselheiras são do sexo feminino, portanto a predominância é de homens neste Conselho. A faixa etária 
predominante é entre 51-60 anos, e três estão na faixa de 31-50. O tempo de atuação no turismo varia de 8 a 30 anos, porém vale destacar que uma conselheira tem mais de 50 anos na área. Ao serem questionados sobre a oferta de atrativos históricos em Manaus que possibilitem a criação de novos roteiros turísticos, todos foram unânimes em dizer que, sim, existem, e há possibilidade para isso, destacando as características de produtos compostos do binômio natureza e cultura. O interessante é mencionar que um dos conselheiros chamou atenção para a existência de vários ícones para comercialização dos roteiros, no entanto existe a necessidade de um esforço conjunto entre as iniciativas públicas e privadas para viabilidade de novas opções de roteiros. Quando perguntados se a Avenida 7 de Setembro tinha representatividade em seu percurso para um roteiro histórico interpretativo, todos apresentaram respostas positivas e enfatizaram que a segmentação de mercado turístico mais adequada para essa proposta de roteirização enquadrava-se na segmentação histórico-cultural.

Com a finalidade de avaliar a percepção deles a respeito dos elementos da paisagem que mereciam destaque no itinerário da avenida, é importante frisar que, dos oito respondentes, apenas dois não assinalaram a alternativa "conjunto arquitetônico (edificações e avenida)", os demais acharam relevantes todos os itens: prédios, praças, pontes e a perspectiva de conjunto. Mesmo assim, os seus comentários são focados nas edificações de forma individual, e não na historicidade da construção da própria avenida, o que denota um olhar despercebido para essa potencialidade interpretativa do patrimônio que precisa ser desvelada para seus visitantes, principalmente o trade turístico local, que é responsável pelo fomento e formatação de roteiros turísticos. Em relação aos pontos de fragilidade, a falta de segurança, limpeza, sinalização turística, retirada dos ambulantes, iluminação, manutenção dos prédios e divulgação foram os itens apresentados pelos conselheiros. Cabe destacar as observações técnicas da representante da Abav, que afirmou ser necessário atentar para a escolha do público-alvo, da faixa etária e das paradas para o guia de turismo explanar, no caso de roteiro a pé; e que, caso se opte pelo modal rodoviário, este "não terá viabilidade em função de não ter como parar nos pontos para descerem, fotografarem e muito menos reduzir a velocidade, pois atrapalharia o trânsito". Agora, essa mesma associação relata que os aspectos importantes na formatação do roteiro da avenida, pensando na viabilidade mercadológica, são a história da cidade, a memória e seus arquivos para não cair no esquecimento, promovendo o sentimento de pertencimento nos residentes.

A Manauscult, por meio de seu conselheiro, destacou como pontos frágeis para a criação desse roteiro o calçamento irregular, que dificulta roteiros a pé, e a ausência de identificação nos principais atrativos turísticos. Em compensação, ao exaltar os pontos relevantes, trouxe um pensamento inovador ao citar "a formatação de um roteiro que possa ser realizado pelo próprio turista, autoexplicativo e trilíngue, sem necessidade de auxílio de guias de turismo". Os demais respondentes destacaram como pontos importantes para viabilizar o roteiro: a sinalização dos atrativos mais significativos, divulgação nos hotéis da cidade, destaque para os trilhos dos bondes da época, infraestrutura de apoio, incentivo por parte do poder público, grau de uso, representatividade, estado de conservação das edificações históricas e apoio local. Após a análise da visão do Comtur-Manaus, faz-se necessário o cruzamento desses resultados com os princípios basilares do processo de qualificação interpretativa do patrimônio cultural.

Com esse intuito de integração e sob a égide das categorias de análise da carta de Icomos (2008) sobre interpretação patrimonial, apresenta-se uma aplicação prática dos conceitos propostos por esse conselho em relação à avenida e seu entorno: 
1. Interpretação: não há publicações impressas e eletrônicas nem instalações sobre a história da avenida, tampouco dos seus prédios, monumentos, praças e pontes. No entanto, desde 2012, pelo menos uma vez ao ano discentes do curso de Turismo realizam o roteiro da avenida, tendo como público-alvo alunos do ensino médio das escolas públicas estaduais, como parte do conteúdo avaliativo da disciplina de Técnicas e Práticas de Guia do curso de Turismo da Universidade do Estado do Amazonas (UEA). O público é conduzido pelos alunos e sob supervisão da professora da disciplina. 2. Apresentação: até a presente data, não ocorre. Portanto a sugestão é a inserção de painéis ilustrados com textos que remetam à evolução do logradouro e apresentações culturais nas praças e nos parques localizados na avenida para possibilitar ao visitante (turistas ou residentes) uma interação com a memória e o presente do lugar, além da contemplação do entorno da paisagem e visitas aos centros culturais com estrutura para a visitação (guiamento, cafés, lanchonetes, museus, banheiros, espaços para descanso etc.). 3. Infraestrutura interpretativa: no que se refere às instalações físicas, equipamentos e espaços patrimoniais, existe uma deficiência nas edificações que compõem o roteiro, porém, quando se refere à avenida como um todo, a ausência é total. 4. Intérpretes do patrimônio: não se constatou essa qualidade nos intérpretes atuais conforme a pesquisa de campo, necessitando, portanto, de capacitação específica de interpretação patrimonial para mostrar o seu real valor e significado. Os guias e monitores dos prédios abertos à visitação não apresentam a história da avenida, e as informações sobre as edificações são repassadas de forma muito mecânica. 5. Sítio de patrimônio cultural: nesse ponto, a avenida em seu conjunto resguarda e conserva todas as singularidades referentes à identidade, ao sentido de lugar de memória das origens da cidade, paisagem cultural, complexo arquitetônico e estrutura reconhecida como sítio histórico.

Como complementação, Boullón (2002) classifica os roteiros em três tipos, de acordo com sua função: a) de traslado; b) de passeio em veículo e c) de passeio a pé. Os roteiros de traslado são aqueles que devem ser percorridos para vencer as distâncias mais longas, como as que separam das zonas hoteleiras os aeroportos, portos, terminais de ônibus e de trens. Já os roteiros de passeio em veículo são aqueles que devem ser selecionados para compor o percurso de city tours, e os roteiros para pedestres são os que conectam os atrativos turísticos próximos e definem os circuitos dentro dos bairros. O roteiro sugerido na Avenida 7 de Setembro pode ser operacionalizado por meio do passeio a pé e ser organizado em grupos guiados por intérpretes ou de forma autoguiada, com auxílio de guias turísticos, mapas e dispositivos eletrônicos com QR Code. Essa proposta autoguiada tem como função garantir mais uma opção para ampliação da experiência, segundo sugestão do próprio Comtur. O público-alvo: máximo de 10 pessoas em grupo (um guia e uma pessoa de apoio para coordenar o grupo) ou individual, podendo ser adultos, jovens e crianças (a partir de 10 anos). Algumas restrições às pessoas com necessidades especiais, em função da falta de acessibilidade nas calçadas e de determinados atrativos, além de guias especializados.

O itinerário contempla 14 pontos com extensão total de 2.430 metros, sendo: a história da avenida (pré-colonial + colonial + imperial + república); Paço da Liberdade; Praça Dom Pedro II; Palácio Rio Branco; Igreja da Matriz; Biblioteca Pública; Praça Heliodoro Balbi; Colégio D. Pedro II; Palacete Provincial; Palácio Rio Negro; Parque Jeferson Péres; Penitenciária Raimundo Vidal Pessoa; Ponte Benjamin Constant; e Largo do Mestre Chico. Para efeito de ordenação e melhor compreensão da avenida e das edificações do seu entorno, o roteiro foi dividido em cinco conjuntos urbanos: ponto inicial - A) Conjunto Arquitetônico, Paisagístico e Arqueológico do 
entorno do Paço da Liberdade; B) Conjunto Arquitetônico e Paisagístico da Igreja da Matriz Nossa Sra. da Conceição; C) Conjunto Arquitetônico e Paisagístico do entorno do Palacete Provincial; D) Conjunto Arquitetônico e Paisagístico do entorno do Palácio Rio Negro; e ponto final - E) Conjunto Arquitetônico e Paisagístico do entorno da Ponte Benjamin Constant. Ressalta-se que o sentido a ser percorrido nesse roteiro turístico deve ser CENTRO-CACHOEIRINHA (Ponto A ao E), pois, desta forma, será reproduzida a ambiência histórica e evolutiva da Avenida 7 de Setembro e seu entorno, ou seja, das origens da cidade até o momento contemporâneo, passado e presente, antigo e moderno, em uma perspectiva dialética. Para os roteiros a pé deve-se levar em consideração a disposição geográfica dos atrativos turísticos, infraestrutura (dias e horários de visitação nas edificações abertas ao público no período de 2018) e a segurança na área em questão. Sugere-se que o roteiro seja executado no período matutino, a partir das $9 \mathrm{~h}$, de terçafeira a sexta-feira; sua duração pode variar conforme as necessidades de cada turista, porém a média, conforme experiência já realizada com alunos, é de 3 horas por grupo.

O roteiro da Avenida 7 de Setembro tem uma temática voltada ao turismo cultural, reunindo nesse logradouro e no seu entorno os principais aspectos evolutivos, históricos, culturais, urbanísticos e sociais da sociedade manauara e do Amazonas. Contextualizá-lo no aspecto promocional da atividade turística da cidade pode proporcionar um resgate da memória e valorização da autoestima, gerando diferenciais e o ordenamento da oferta turística dos atrativos culturais do local.

\section{CONSIDERAÇÕES FINAIS}

O homem desenvolve processos de apropriação do espaço por meio da articulação de seus saberes e, assim, forma a constituição física e cultural de um local; dessa relação do homem com a natureza, surgem os atrativos turísticos. Na realidade, para entender a paisagem, deve-se considerála com uma estrutura de interação em constante movimento, com a finalidade de compreendê-la em sua essência naturalmente cultural. Trazendo essa questão para o objeto de pesquisa, observa-se que os moradores de Manaus e os visitantes frequentam a maioria das edificações contextualizadas neste trabalho, mas sua compreensão limita-se aos aspectos individuais de cada atrativo.

Desta forma, o efetivo desenvolvimento local de um destino turístico precede de uma interação entre a atratividade e os visitantes, além de um sentimento de pertencimento nos residentes. A interpretação das transformações antigas e contemporâneas da cidade de Manaus por meio de uma avenida, as reflexões dessa formação na perspectiva de conjunto por intermédio da proposta de roteirização e, ainda, a ampliação dessa compreensão espacial e histórica da Avenida 7 de Setembro poderão auxiliar na construção do sentimento de pertença nos membros da localidade e diversificação da oferta de atrativos turísticos manauaras. O diálogo entre patrimônio e turismo é uma simbiose que favorece a conservação e as singularidades culturais de um lugar.

A evolução da Avenida 7 de Setembro em conjunto com a paisagem urbana edificada do seu entorno dentro de uma relação espaço-tempo confere uma das principais contribuições científicas desta pesquisa. Isso deve ser entendido como um processo de aprendizagem e interpretação do lugar, saindo do aspecto físico e compreendendo que aquele prédio, rua ou avenida faz parte de um contexto maior nas escalas locais, estaduais, regionais, nacionais e internacionais. O resgate da sua construção, em conformidade com o seu entorno até os tempos atuais, é o registro da relação de passado e presente, em que os principais momentos da memória da cidade são materializados nessa avenida, produto dessa sociedade em constante crescimento e movimento. 
Diante dos resultados no presente artigo, convém mencionar que a principal limitação encontrada foi que, das 12 instituições que compõem o Comtur-Manaus, cinco não devolveram os questionários com suas percepções sobre a proposta de roteirização turística da avenida. Isso não inviabiliza o presente estudo, pois houve a participação da Associação Brasileira de Agências de Viagens (ABAV-AM) na pesquisa, de forma representativa e positiva no que tange à proposta apresentada, além das outras entidades que favoravelmente encontram-se sensíveis a essa possibilidade. Como legado para o trade turístico e para a sociedade, esse trabalho deixa como recomendação a implantação do roteiro da Avenida 7 de Setembro, que pode ser utilizado tanto pela iniciativa privada como pública. Sua concretização incrementará a oferta de atrativos turísticos do destino Manaus, oferecendo outro olhar para o Centro Histórico, de forma que essa interação entre patrimônio e turismo traga a possibilidade de desenvolvimento local do destino em consonância com sua respectiva conservação, fortalecendo os laços comunitários e o cuidado para a preservação de suas características culturais.

\section{REFERÊNCIAS}

ANDRADE, Cyntia. Lugar de memória... memórias de um lugar: patrimônio imaterial de Iguatu, Andaraí, BA. Passos Revista de Turismo y Patrimonio Cultural, Andaraí, BA, v. 6, n. 3, p. 569-90, fev./jul. 2008.

BAHL, Miguel. Viagens e roteiros turísticos. 1. ed. Curitiba: Protexto, 2004.

BOULLÓN, Roberto. Planejamento do espaço turístico. 2. ed. Bauru, SP: Edusc, 2002.

BRASIL. Ministério do Turismo. Inventário da Oferta Turística. Brasília-DF, 2011.

BRASIL. Constituição da República Federativa do Brasil de 1988. Brasília-DF, 1988. Disponível em: http:// www.planalto.gov.br/ccivil_03/Constituicao/Constituicao.htm. Acesso em: 2 ago. 2018.

BRASIL. Decreto-Lei n. 288, de 28 de fevereiro de 1967. Zona Franca de Manaus. Brasília-DF, 1967. Disponível em: http://www.planalto.gov.br/ccivil_03/Decreto-Lei/Del0288.htm. Acesso em: 2 ago. 2018.

BRASIL. Decreto-Lei n. 25, de 30 de novembro de 1937. Organiza a proteção do Patrimônio Histórico e Artístico Nacional. Brasília-DF, 1937. Disponível em: http://www.planalto.gov.br/ccivil_03/decreto-lei/ del0025.htm. Acesso em: 2 ago. 2018.

BRASIL. Constituição da República Federativa do Brasil. Brasília-DF, 1934. Disponível em: http://www. planalto.gov.br/ccivil_03/constituicao/constituicao34.htm. Acesso em: 2 ago. 2018.

CÁNOVAS, Elisa Rico. La correspondencia entre la construcción de experiencias auténticas y la interpretación del patrimonio. Reflexiones desde la autenticidad existencial. Pasos Revista de Turismo y Patrimonio Cultural, Alicante, ES, v. 14, n. 2, p. 495-508, abr. 2016.

CARVALHO, Karoliny Diniz; COELHO, Suzana; BONFIM, Natanael Reis. Turismo cultural e interpretativo na cidade de Ilhéus-Bahia: uma proposta de revitalização para a Avenida Soares Lopes. Caderno Virtual de Turismo, Ilhéus, BA, v. 11, n. 2, p. 205-18, ago. 2011.

CASTRIOTA, Leonardo Barci. Patrimônio: conceitos e perspectivas. In: BESSA, Altamiro S. M. (Coord.). Preservação do patrimônio cultural: nossas casas e cidades, uma herança para o futuro. 1. ed. Belo Horizonte: Crea-MG, 2004. p. 9-13. 
CHOAY, Françoise. A alegoria do patrimônio. 4. ed. São Paulo: Estação Liberdade, 2001.

CHUVA, Márcia (Org.). História e patrimônio: entre o risco e o traço, a trama. Revista do Patrimônio Histórico e Artístico Nacional, Curitiba, PR, n. 34, p. 11-24, abr. 2012.

DANTAS, Fabiana Santos. O patrimônio cultural protegido pelo Estado Brasileiro. In: CAMPOS, Juliano Bittencourt; PREVE, Daniel Ribeiro; SOUZA, Ismael Francisco de. (Ed./Org.). Patrimônio cultural, direito e meio ambiente: um debate sobre a globalização, cidadania e sustentabilidade. 1. ed. Curitiba: Multideia, 2015. p. 30-40.

DORSA, Arlinda Cantero; CASTILHO, Maria Augusta de; SANTOS, Maria Christina de Lima Félix. Artesanato de etnias indígenas: patrimônio cultural de Mato Grosso do Sul. Revista Interações, Campo Grande, MS, v. 16, n. 2, p. 467-73, jul./dez. 2015.

FONSECA. Maria Cecília Londres. O patrimônio em processo: trajetória da política federal de preservação no Brasil. Rio de Janeiro: UFRJ/Iphan, 1997.

FUNARI, Pedro Paulo; PELEGRINI, Sandra. Patrimônio histórico e cultural. Rio de Janeiro: Jorge Zahar, 2006.

GASTAL, Suzana. Alegorias urbanas: o passado como subterfúgio: tempo, espaço e visualidade na pósmodernidade. Campinas, SP: Papirus, 2006.

GRAMMONT, Ana Maria de. A construção do conceito de patrimônio histórico: restauração e cartas patrimoniais. Pasos: Revista de Turismo y Patrimonio Cultural, El Sauzal (Tenerife), España, v. 4, n. 3, p. 437-42, mar. 2006.

GUIMARÃES, Márcia Raquel Cavalcante; PEREIRA, Raquel Maria Fontes do Amaral. Avenida Sete de Setembro: o retrato de um passado presente e o seu legado para o turismo em Manaus-Amazonas. In: SEMINÁRIO DA ASSOCIAÇÃO NACIONAL DE PESQUISA E PÓS-GRADUAÇÃO EM TURISMO, 9., 2012, São Paulo. Anais [...]. São Paulo: Anptur, 2012. p. 15.

IBORRA, Jose Rubio. La opinión del residente como criterio para la elaboración de rutas turísticas en el entorno urbano mediante SIG. Investigaciones Turísticas, Murcia, ES, v. 0, n. 11, p. 196-215, jun. 2016.

INTERNATIONAL COUNCIL ON MONUMENTS AND SITES (ICOMOS). Carta ICOMOS para Interpretación y Presentación de Sitios de Patrimonio Cultural. 16a Assembleia Geral do Icomos, Québec (Canadá), 4 de outubro de 2008.

LE GOFF, Jacques. Introduction des entretiens du patrimoine. Patrimoine et passions identitaires. Paris: Fayard, 1998.

LEAL, Claudia Feierabend Baeta. Patrimônio e desenvolvimento: as políticas de patrimônio cultural nos anos 1960. Anais do Museu Paulista: História e Cultura Material, São Paulo, v. 24, n. 1, p. 99-136, jan./ abr. 2016.

LÓPEZ, Ana Mesía. Propuesta de itinerario turístico para una ciudad histórica a partir de las figuras de protección patrimonial de sus inmuebles. Un ensayo para el municipio de Padrón (A Coruña). Pasos Revista de Turismo y Patrimonio Cultural, El Sauzal, Tenerife, v. 12, n. 2, p. 479-90, jan./abr. 2014.

MANAUS. Fundação Municipal de Cultura, Turismo e Eventos (Manauscult). Mapa com a delimitação do Centro Antigo de Manaus e o seu sítio histórico. Manaus, 2017. 
MANAUS. Lei Orgânica do Município de Manaus. Manaus: Câmara Municipal, 1990. Disponível: http:// www.dhnet.org.br/direitos/municipais/a_pdf/lei_organica_am_manaus.pdf. Acesso em: 2 ago. 2018.

MARTINS, Anne Bastos; VIEIRA, Gustamara Freitas. Turismo e patrimônio cultural: possíveis elos entre identidade, memória e preservação. Revista A Estação Científica, Juiz de Fora, MG, v. 1, n. 2, p. 1-23, mar. 2006.

MOURA, Angela Acosta Giovanini de. A proteção internacional do patrimônio cultural. Cadernos de Direito, Piracicaba, SP, v. 12, n. 23, p. 91-110, jul./dez. 2012.

MURTA, Stela Maris; GOODEY, Brian. Interpretação do patrimônio para visitantes: um quadro conceitual. In: MURTA, Stela Maris; ALBANO, Celina (Ed./Org.). Interpretar o patrimônio: um exercício do olhar. Belo Horizonte: Ed. UFMG: Território Brasilis, 2002.

PASSARELLI, Silvia Helena; ALVES, Luiz Roberto. Patrimônio cultural: valores e visões na região do Grande ABC. Revista Interdisciplinar de Gestão Social, São Paulo, v. 2, n. 2, p. 111-35, maio/ago. 2013.

PEREIRA, Cecilia Ribeiro. O turismo cultural e as missões UNESCO no Brasil. 2012. 178 p. Tese (Doutorado em Desenvolvimento Urbano) - Universidade Federal de Pernambuco, Recife, 2012.

PORTO, Simona; LEANZA, Paola; CASCONE, Giovanni. Developing Interpretation Plans to Promote Traditional Rural Buildings as Built Heritage Attractions. International Journal of Tourism Research, Catania, IT, v. 14, n. 5, p. 421-36, set./out. 2012.

PRODANOV, Cleber Cristiano; FREITAS, Ernani Cesar de. Metodologia do trabalho cientifico: métodos e técnicas da pesquisa e do trabalho acadêmico. Novo Hamburgo, RS: FEEVALE, 2013.

PUPO, Gerson Herrera. La interpretación del patrimonio cultural para la gestión turística. Retos Turísticos, Camagüey, Cuba, v. 10, n. 1-2, p. 21-7, fev./set. 2011.

REIS, Diego Geovan dos; BAPTISTA, Leandro; CARDOZO, Poliana Fabíula. Educação e interpretação patrimonial: elaboração de um plano interpretativo para a Casa da Cultura de Irati-PR. Turydes Revista Turismo y Desarrollo Local, Irati, PR, v. 9, n. 20, p. 1-20, maio/jun. 2016.

RISCADO, Júlia Erminia. Preservação do patrimônio nas grandes cidades: Morro da Conceição no Centro do Rio de Janeiro e o entorno dos bens tombados (1970-1980). 2013. 117 p. Dissertação (Mestrado em História) - Universidade Federal do Estado do Rio de Janeiro, Rio de Janeiro, 2013.

RODRIGUES, Rita Lages. O patrimônio e o público: reflexões sobre o caráter público-patrimonial das esculturas em Belo Horizonte. In: ROSADO, Alessandra; GONÇALVES, Wili de Barros (Ed./Org.). Ciências do patrimônio: horizontes transdisciplinares. Belo Horizonte: Secretaria de Estado de Cultura de Minas Gerais, Arquivo Público Mineiro, 2015.

SOUZA, Márcio. História da Amazônia. Manaus: Valer, 2009.

TOFFOLO, Regina; CARDOZO, Poliana Fabíula. Interpretação patrimonial como forma de valorização das edificações e o desenvolvimento turístico do município de Lapa (Paraná, Brasil). Turismo \& Sociedade, Lapa, PR, v. 6, n. 4, p. 791-813, out. 2013.

TOMAZ, Paulo Cesar. A preservação do patrimônio cultural e sua trajetória no Brasil. Fênix - Revista de História e Estudos Culturais, Uberlândia, MG, v. 7, n. 2, p. 1-12, maio/ago. 2010.

TORELLY, Luiz. Notas sobre a evolução do conceito de patrimônio cultural. Fórum Patrimônio, Belo Horizonte, MG, v. 5, n. 2, p. 1-18, jul./dez. 2012. 
VOGT, Olgário Paulo. Patrimônio cultural: um conceito em construção. Revista Métis: História \& Cultura, Caxias do Sul, RS, v. 7, n. 13, p. 13-31, jan./jun. 2008.

ZANIRATO, Silvia Helena; RIBEIRO, Wagner Costa. Patrimônio cultural: a percepção da natureza como um bem não renovável. Revista Brasileira de História, São Paulo, v. 26, n. 51, p. 251-62, jan./jun. 2006.

\section{Sobre os autores:}

Márcia Raquel Cavalcante Guimarães: Doutoranda e mestre em Turismo e Hotelaria pela Universidade do Vale do Itajaí (Univali). Turismóloga. Docente da Universidade do Estado do Amazonas (UEA). Pesquisadora do GP-Observatur-UEA. E-mail: mguimaraes@uea.edu.br, Orcid: http://orcid.org/0000-0003-1576-9085

Karla Cristina Ribeiro Maia: Doutoranda em Turismo e Hotelaria na Universidade do Vale do Itajaí (Univali). Mestre em Engenharia de Produção pela Universidade Federal de Santa Catarina (UFSC). Turismóloga. Docente da Universidade do Estado do Amazonas (UEA). Pesquisadora do GP-Observatur-UEA. E-mail: kribeiro@uea.edu.br, Orcid: http://orcid.org/0000-0003-3382-1430

Sibelle da Silva Oliveira: Licenciada em Letras pela Universidade Federal do Amazonas (Ufam). Turismóloga pela Universidade do Estado do Amazonas (UEA). Pesquisadora do GP-Observatur-UEA. E-mail: sso.tur@uea.edu.br, Orcid: http://orcid.org/0000-0002-5520-8381

Luciano Torres Tricárico: Doutor e mestre em Arquitetura e Urbanismo pela Universidade de São Paulo (USP). Professor e pesquisador no Programa de Pós-Graduação de Turismo e Hotelaria da Universidade do Vale do Itajaí (Univali). E-mail: tricarico@univali.br, Orcid: http://orcid.org/0000-0003-3307-8229 
